\title{
Creep Crack Initiation and Growth Behavior in Weldments of high Cr steels
}

\author{
$\underline{\text { Ryuji Sugiura }}^{1}{ }^{, *}$, A. Toshimitsu Yokobori, Jr. ${ }^{1}$, Kazuto Sato ${ }^{1}$, Masaaki Tabuchi ${ }^{2}$ \\ Kenichi Kobayashi $^{3}$, Masataka Yatomi ${ }^{4}$, Kamran Nikbin ${ }^{5}$

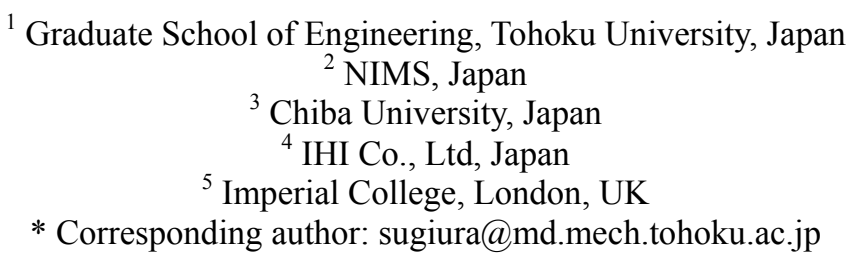

\begin{abstract}
W}$ added high Cr ferritic heat-resistant steels have been developed as a boiler material. Most of boiler component structures are mainly fabricated by welding which are likely to the regions of crack initiation and propagation. However, the method of predicting the life of creep crack initiation and growth have not been clearly established for weldments of high $\mathrm{Cr}$ ferritic heat resistant material due to many factors such as the variation in micro-structures and the residual stress caused by welding and thermal cycles. In the present study, the experiments of creep crack growth using a circular notched round bar specimen with variation of notch location in HAZ were conducted and the characteristics of creep crack growth rate and creep crack initiation life were summarized in terms of $Q^{*}$ parameter, which has been proposed as fracture mechanics parameter to describe creep crack growth rate.
\end{abstract}

Keywords Creep crack initiation, Creep crack growth, Weldment, High $\mathrm{Cr}$ steel, $C^{*}$ parameter, $Q^{*}$ parameter.

\section{Introduction}

The $\mathrm{W}$ added high $\mathrm{Cr}$ ferritic heat-resistant steels have been developed as a boiler material. Most of boiler component structures are mainly fabricated by welding which are likely to the regions of crack initiation and propagation. However, the method of predicting the life of creep crack initiation and growth have not been clearly established for weldments of high $\mathrm{Cr}$ ferritic heat resistant material due to many factors such as the variation in micro-structures and the residual stresses caused by welding and thermal cycles.

In the previous work, we have reported that creep crack grows initially in the oblique direction to the direction of initial notch with 45 degree as it approaches the site of minimum hardness region near the boundary between base metal (BM) and heat affected zone (HAZ) [1-3], as shown in Fig. 1, by conducting the tests using a C(T) specimen for P92 weldment. Correspondingly, the site of maximum value of stress multiaxiality shifts to the site of minimum hardness. This process was defined as the incubation process of creep crack growth. Therefore, we suggested that in order to predict the fracture life for weldment, it is important to clarify the incubation process and path on a structural mechanical basis in order correctly determine the incubation time of creep crack growth. In the present study, more detailed experiments of creep crack growth using a circular notched round bar specimen with variation of notch location in HAZ were conducted and the characteristics of creep crack growth rate and creep crack initiation life were summarized in terms of $Q^{*}$ parameter, which has been proposed as fracture mechanics parameter to describe creep crack growth rate.

The present work is closely concerned with the Japanese result for the VAMAS Project and JSPS 129 Committee.

\section{Creep crack growth test procedures}

The material used is $\mathrm{W}$-added $9 \% \mathrm{Cr}$ ferritic heat-resistant steel (ASME Code Case 2179 , ASTM A335 P92) and its plate of $31 \mathrm{~mm}$ thickness, which was subjected to normalizing at $1343 \mathrm{~K}$ for $2 \mathrm{hr}$ 


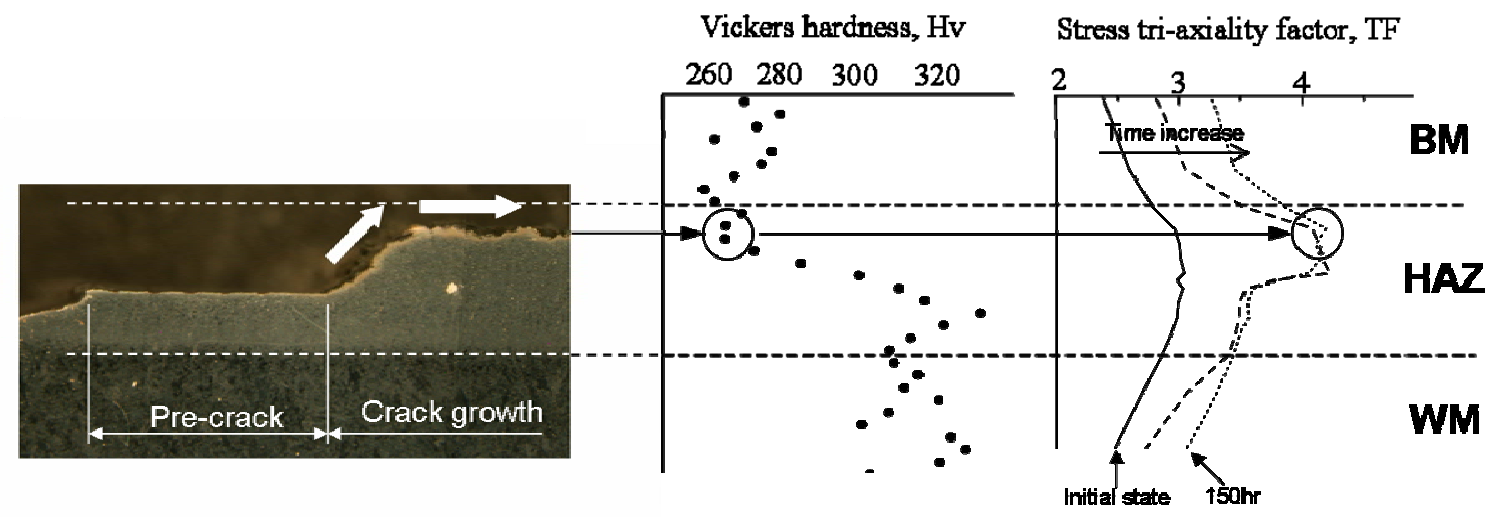

Figure 1. Comparison of creep crack growth path, Vickers hardness and stress tri-axiality for weldment of P92

and tempering for $2 \mathrm{hr}$, was prepared as a base metal (BM). The chemical composition is shown in Table 1. The welded joint (WM) was fabricated using multi-layer gas tungsten arc (GTA) welding with single bevel of $20^{\circ}$ [4]. Welding consumable used for GTA welding was matching filler wire developed recently for welding this class of steel [5]. Finally, the post weld heat treatment (PWHT) was carried out at $1013 \mathrm{~K}$ for $4 \mathrm{hr}$. The process parameters of multi-layer GTA welding are given in Table 2 [4].

The specimen used was manufactured into a circular notched round bar specimen, as shown in Fig. 2. For the welded joint specimen, two kinds of specimen with variation in the notch location such as one located in the middle part of HAZ and the other in the interface of fine-grained HAZ and base metal in the region of HAZ were prepared, as shown in Fig. 2.

Creep crack growth tests were performed using a lever arm creep testing machine of Type RT-30 manufactured by TOSHIN KOGYO. The test temperatures were kept at a specified temperature with the precision of $\pm 2^{\circ} \mathrm{C}$. The experimental conditions are shown in figures of experimental results. The crack length was measured by electrical potential method [6-8]. The creep crack growth tests were conducted based on ASTM E1457-07 [9] and JSPS standards [10].

\section{Characteristics of creep crack length and deformation}

The relationship between creep crack length $\Delta a$ and non-dimensional time $t / t_{f}$ of each specimen for weldment is shown in Fig. 3. The relationship between load line displacement $\Delta \delta$ and non-dimensional time $t / t_{f}$ of them is shown in Fig. 4, where $t$ and $t_{f}$ are the current time of load application and the life of creep crack growth for each specimen.

From the creep crack initiation and growth tests, fracture lives for both specimens such as one located in the middle part of HAZ and the other in the interface of BM and fine-grained HAZ in the region of HAZ are the same and the characteristics of creep crack growth show the similar, as shown in Fig. 3. From these results mentioned above, even though notch was located in the lower hardness region, creep crack growth was found not to be immediately accelerated. This shows the possible presence of an incubation time of creep crack growth even if the notch was located in the interface between base metal and fine-grained HAZ in the region of HAZ, which corresponds to the region of minimum hardness.

However, specimen with the notch located in the interface between base metal and fine-grained $\mathrm{HAZ}$ in the region of HAZ shows the ability to deform. 
Table 1. Chemical composition of P92 steel in wt. \%

\begin{tabular}{cccccc}
\hline $\mathrm{C}$ & $\mathrm{Si}$ & $\mathrm{Mn}$ & $\mathrm{P}$ & $\mathrm{S}$ & $\mathrm{Cr}$ \\
\hline \hline 0.09 & 0.16 & 0.47 & 0.01 & 0.001 & 8.72 \\
\hline $\mathrm{Mo}$ & $\mathrm{W}$ & $\mathrm{V}$ & $\mathrm{Nb}$ & $\mathrm{B}$ & $\mathrm{N}$ \\
\hline \hline 0.45 & 1.87 & 0.21 & 0.06 & 0.002 & 0.05 \\
\hline
\end{tabular}

Table 2. Process parameters of multi-layer GTA welding

\begin{tabular}{cc}
\hline groove & single bevel $20^{\circ}$ \\
\hline preheating & $>373 \mathrm{~K}$ \\
\hline welding current & $200 \sim 250 \mathrm{~A}$ \\
\hline arc voltage & $10 \sim 10.5 \mathrm{~V}$ \\
\hline welding speed & $1.2 \sim 1.5 \mathrm{~mm} / \mathrm{s}$ \\
\hline multi-layer & $33 \sim 37 \mathrm{pass}$ \\
\hline
\end{tabular}

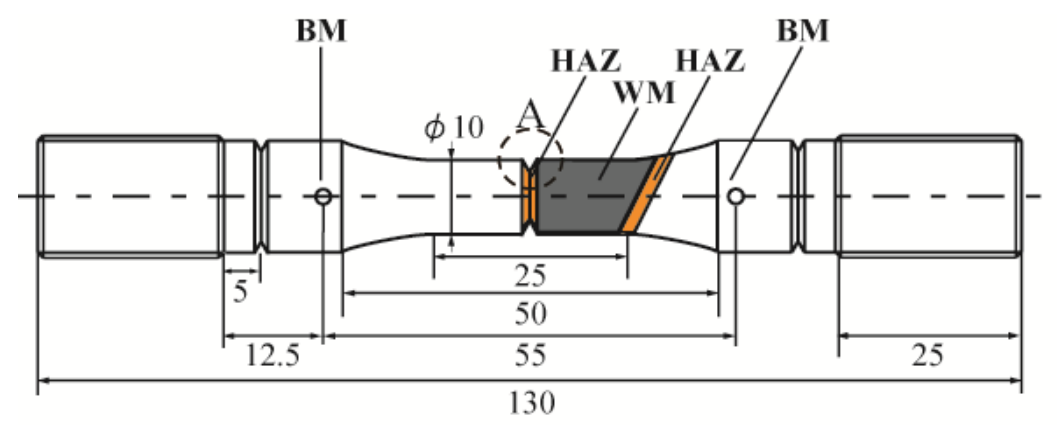

(a) The geometry and size of a circular notched specimen for weldment

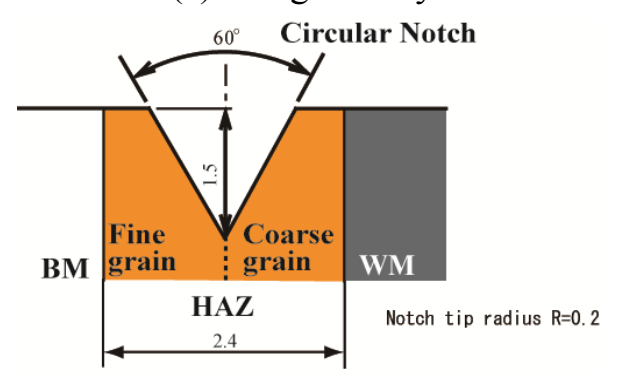

Detail of the notch part A

(b) Circular notch located in the middle part of HAZ

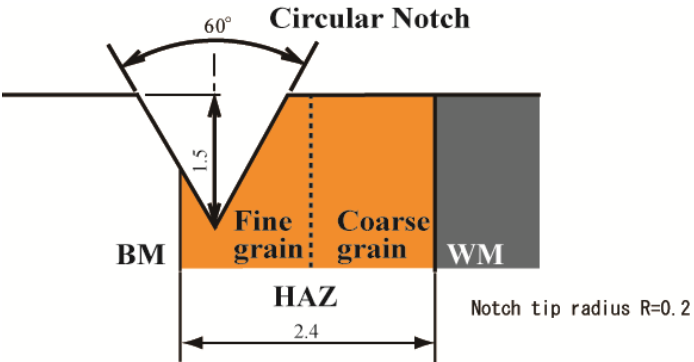

Detail of the notch part A

(c) Circular notch located in the interface between base metal and fine-grained HAZ

Figure 2. The geometry and size of a circular notched specimen for weldment and variation in the notch location in HAZ

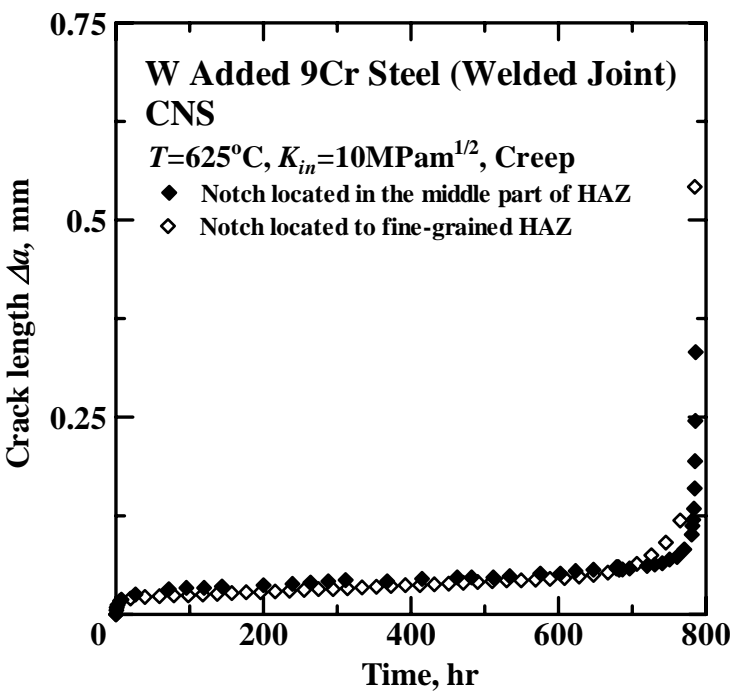

Figure 3. Characteristic of creep crack length

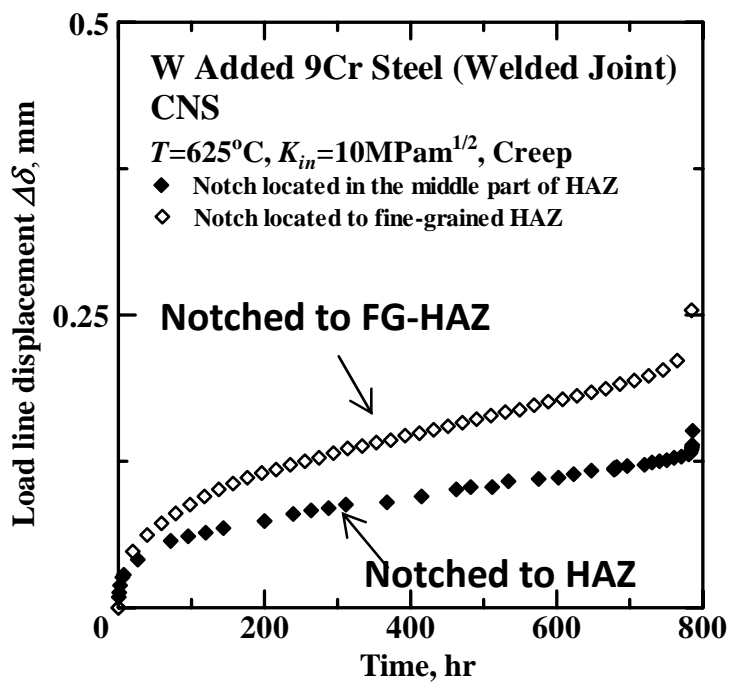

Figure 4. Characteristic of load line displacement 


\section{Creep crack growth rate characteristics}

$C^{*}$ [11-14], $d \delta / d t$ [15-17] and $Q^{*}$ [18-19] have been proposed as the fracture mechanics parameter to describe the creep crack growth rate. The $C^{*}$ parameter for a circular notched specimen is given by Eq. (1).

$$
C^{*}=\frac{2 n+1}{2 n-1} \sigma_{n e t} \frac{d \delta}{d t},
$$

where $n$ is creep exponent, $\sigma_{\text {net }}$ is the net section stress (MPa).

The creep crack growth data for both base metals and weldmens (indication data are for the specimen with notch located in the middle part of HAZ) estimated by $C^{*}$ and $d \delta / d t$ are shown in Figs. 5 and 6 , respectively. The characteristics of creep crack growth rate estimated by $C^{*}$ and $d \delta / d t$ show typical dual behavior which takes major portion of total crack growth life, approximately $60-70 \%$ of total life. An example of dual behavior on $C^{*}$ is shown in Fig. 7.

By the way, $Q^{*}$ concept enables crack growth in the steady state regions, which correspond to the circular region in Fig. 7, to be characterized uniquely [18-19].

The creep crack growth rate for creep-brittle materials is represented by the $Q^{*}$ parameter as follow [19],

$$
\frac{d a}{d t}=A \exp \left(Q^{*}\right)=A^{*} K_{i n}^{n} \exp \left(-\frac{\Delta H_{g}}{R T}\right),
$$

where $A$ and $A^{*}$ are constant, $K_{\text {in }}$ is the initial stress intensity factor $\left(\mathrm{MPam}^{1 / 2}\right), n$ is the exponent of initial stress intensity factor, $\Delta H_{g}$ is an activation energy $(\mathrm{kJ} / \mathrm{mol}), R$ is the gas constant $(=8.3145 \mathrm{~J} / \mathrm{Kmol}), T$ is the absolute temperature $(\mathrm{K})$.

By taking logarithms of both sides of Eq. (2), Eq. (3) is obtained.

$$
\log \frac{d a}{d t}=\log A^{*}+\left[n \log K_{\text {in }}-\frac{\Delta H_{g}}{R T}\right] .
$$

The bracket portion of Eq. (3) corresponds to the $Q^{*}$ parameter which has been proposed as an estimation parameter of creep crack growth rate [18].

On the basis of $Q^{*}$ concept, creep crack growth rate in this region is well predicted for base metals and weldments including the data for specimen with the notch located in the fine-grained HAZ, as shown in Fig. 8, regardless of the life of creep crack growth are different between them.

\section{Characteristic of creep crack growth life}

In the section 3, the possible presence of an incubation time of creep crack growth, regardless of variation in notch location, was shown and we suggested that in order to predict the fracture life for weldment, it is important to clarify the incubation process in order correctly determine the incubation time of creep crack growth. The comparison of creep crack growth behavior for weldment with that for base metal under the same condition $\left(T=625^{\circ} \mathrm{C}, K_{i n}=12 \mathrm{MPam}^{1 / 2}\right)$ is shown in Fig. 9. In Fig. 9, in spite of the fact that the creep crack growth rate in the constant region of creep crack growth both for weldment and base metal are the same, the life of creep crack growth for WM was shorter than that for BM. This will be due to the occurrence of the rapidly acceleration of creep crack growth for WM. In Fig. 9, the region of restrained creep crack growth rate due to the HAZ will correspond to the crack length of $100 \mu \mathrm{m}$. Therefore, this region is considered to be within an incubation region of creep crack growth which can be termed creep crack initiation for circular notched round bar specimen. 


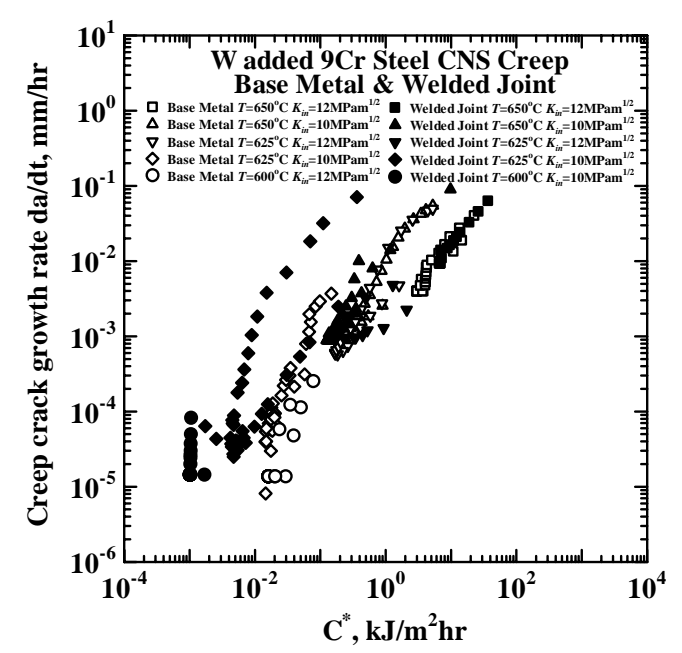

Figure 5. Characterization of creep crack growth rate estimated by $C^{*}$ parameter

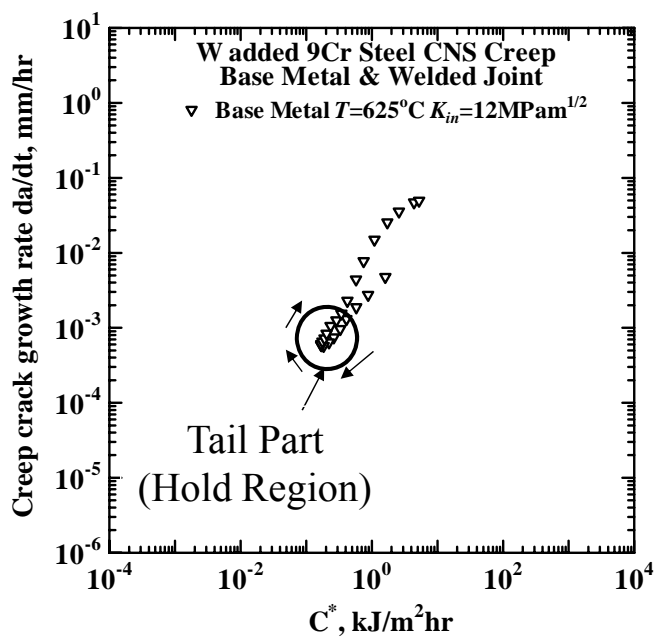

Figure 7. Example of creep crack growth data of base metal on $C^{*}$ parameter

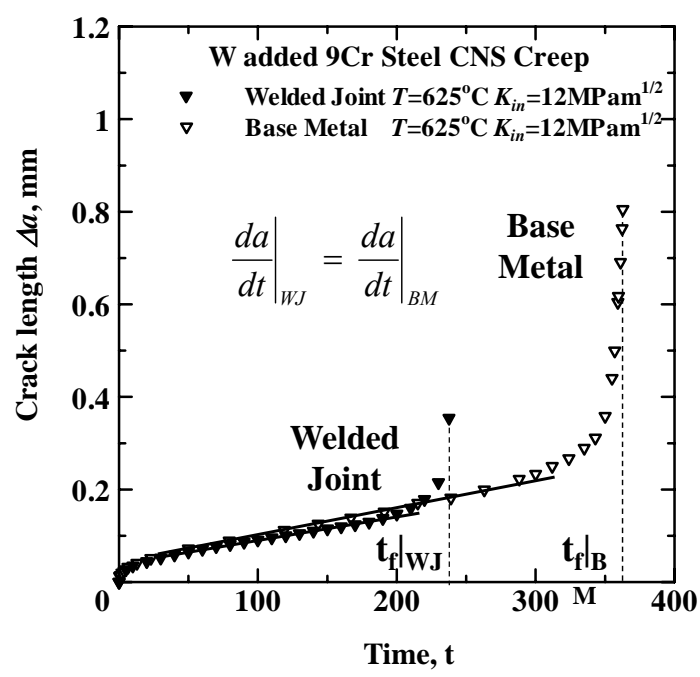

Figure 9. Comparison of creep crack growth behavior for base metal with that for weldment

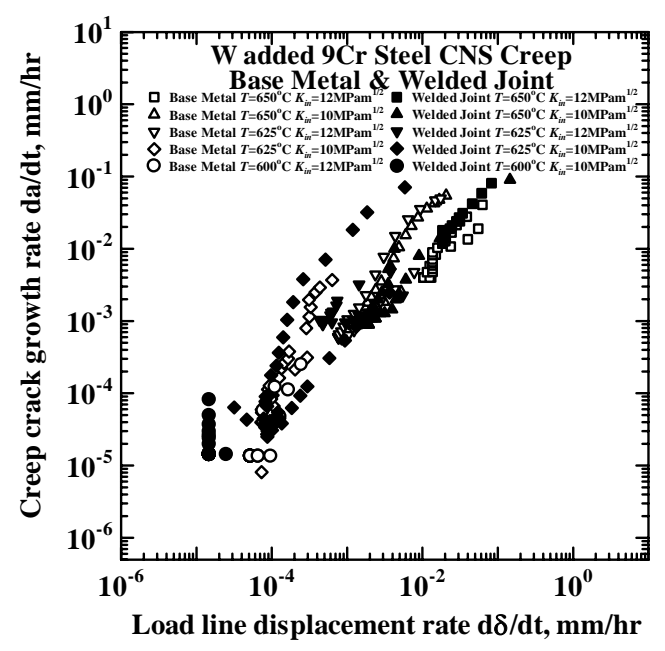

Figure 6. Characterization of creep crack growth rate estimated by $d \delta / d t$ parameter

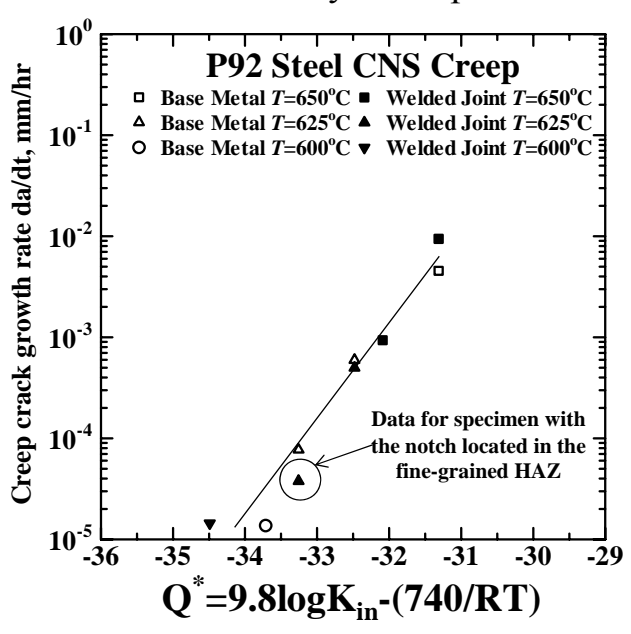

Figure 8. Characterization of creep crack growth rate estimated by $Q^{*}$ parameter

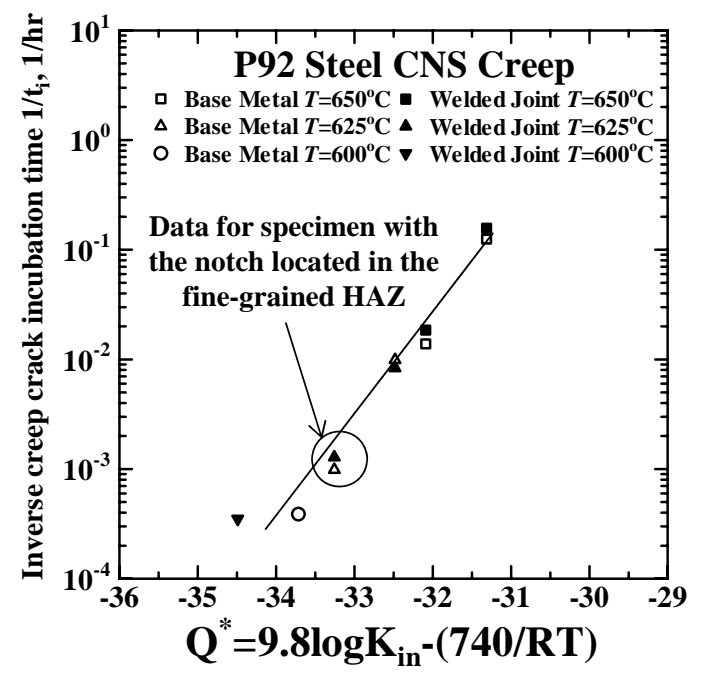

Figure 10. Creep crack initiation life estimated by $Q^{*}$ parameter 
The creep crack initiation times were estimated by $Q^{*}$ parameter, as show in Fig. 10. In Fig. 10, $Q^{*}$ was found to correlate uniquely creep crack initiation for weldment of P92 steel, including of the data for specimen with the notch located in the fine-grained HAZ.

\section{Conclusions}

By conducting more detailed experiments of creep crack growth using a circular notched round bar specimen with variation of notch location in HAZ, the possible presence of an incubation time of creep crack growth was shown, regardless of variation in notch location. We suggested that in order to predict the fracture life for weldment, it is important to clarify the incubation process in order correctly determine the incubation time of creep crack growth. Additionally, the characteristics of creep crack growth rate and creep crack initiation life were summarized in terms of $Q^{*}$ parameter.

\section{References}

[1] R. Sugiura, A. T. Yokobori, Jr., K. Sato, M. Tabuchi, M. Yatomi, K. Kobayashi and K. Nikbin, Strength, Fracture and Complexity, An Int. J., 6 (2011) 177-189.

[2] R. Sugiura, A. T. Yokobori, Jr., K. Suzuki and M. Tabuchi, Eng. Frac. Mech., 77 (2010) 3053-3065.

[3] A.Toshimitsu Yokoboti. Jr., Ryuji Sugiura, Masaaki Tabuchi, Masataka Yatomi, Kenichi Kobayashi, Kamran Nikbin, Strength, Fracture and Complexity, An Int J., 7 (2011/2012) 315-320.

[4] M. Matsui, M. Tabuchi, T. Watanabe, K. Kubo, J. Kinugawa. Degradation of creep strength in welded joint of 9\%Cr steel. ISIJ Int. 2001; 41 Supplement: S126-130.

[5] K. Ogawa, A. Iseda, Y. Sawaragi, S. Masumoto, F. Masuyama. Development of high strength $12 \% \mathrm{Cr}$ steel pipe and tubes for boilers. Sumitomo Metals Japan. 1995;47:39-46.

[6] H.H. Johnson, "Calibrating the electric potential method for studying slow crack growth," Materials Research and Standard, 5 (1965) 442-445.

[7] K.H. Schwalbe, and D. Hellman, "Application of the Electrical Potential Method to Crack Length Measurements Using Johnson's Formula," J. of Testing and Evaluation, 9, 4 (1980) 218-220.

[8] T. Adachi, A.T. Yokobori, Jr., M. Tabuchi, A. Fuji, T. Yokobori and K. Nikbin, "The Proposal of $Q^{*}$ Parameter and Derivation of the Law of Creep Crack Growth Life for a Round Bar Specimen with a Circular Notch for Cr-Mo-V Steel," Materials at High Temperatures, 21, 2, (2004) 95-100.

[9] ASTM E1457-07, 2007, "Standard Test Method for Measurement of Creep Crack Growth Times in Metals".

[10] T. Yokobori, T. Iwadate, S. Konosu, M. Tabuchi, A. Fuji, A.T. Yokobori Jr., Strength of materials and fractology, 129 Committee of JSPS: Sasaki Press Japan, 1999, p.291.

[11]J.D. Landes, and J.A. Begley, "A Fracture Mechanics Approach to Creep Crack Growth," ASTM STP., 590 (1976) 128.

[12]K. Ohji, K. Ogura and S. Kubo, Japan Soc. Mech. Engng., 44 (1975) 183. (in Japanese)

[13] S. Taira, R. Ohtani, and T. Kitamura, "Application of J-Integral to High-Temperature Crack Propagation", Trans. ASME J. Engng. Mater. Technol., 101 (1979) 154-167.

[14]R. Koterazawa, and T. Mori, "Applicability of Fracture Mechanics Parameters to Crack Propagation Under Creep Condition”, Trans. ASME J. Engng. Mater. Technol., 99, (1977) 298-305.

[15]A. Fuji, and M. Kitagawa, "A comparison of creep crack growth behavior in Nickel based superalloy with low alloy steel”, Advances in Fracture and Structural Integrity., Prof. of ICF8, V. V. Panasyuk editor., (1994) 487.

[16]B. Dogan, and K.H. Schwalbe, "Creep Crack Growth Behavior of Ti-6242", ASTM 
Symposium Proc. ASTM STP 1131, H.A.Ernst et al., eds., Philadelphia, (1992) 284-296.

[17]A.T. Yokobori, Jr., T. Yokobori, T. Kuriyama, T. Kako, Y. Kaji, "Characterization of high temperature creep crack growth rate in terms of independent parameters", Proc. of the Int. Conf. on Creep, JSME, I Mech E, ASME., (1986) 135-140.

[18]A.T. Yokobori, Jr., T. Yokobori, "New concept to crack growth at high temperature creep and creep-fatigue," Advances in Fracture Research, Proc. ICF7, K. Salama et al., eds., Pergamon Press, 2, (1989) 1723-1735.

[19]A.T. Yokobori, Jr., T. Uesugi, T. Yokobori, A. Fuji, M. Kitagawa, I. Yamaya, M. Tabuchi, and K. Yagi, "Estimation of creep crack growth rate in IN-100 based on the $Q *$ parameter concept", J. of Materials Science, 33 (1998) 1555-1562. 